\title{
Penulisan Operasi Hitung dalam Bahasa Inggris melalui Game Take A Number
}

\author{
Riris Sugianto ${ }^{1}$, Baiq Yuni Wahyuningsih ${ }^{2}$, Reny Wardiningsih ${ }^{3}$ \\ Universitas Teknologi Mataram \\ sugiantoriris87@gmail.com
}

\begin{abstract}
The implementation of this activity was carried out with the aim of improving the ability of ASM Mataram Banking Administration Management students in writing arithmetic operations using English both in mathematical notation and writing bundreds (bundreds) and thousands (thousands) in English. The stages of this activity begin with the initial stage (preparation), the core stage (implementation) and the final stage (evaluation). The initial stage is the preparation, at this stage the initial observation, the collection of material about the procedures for writing mathematical operations in English both writing mathematical notation and writing numbers in English and is equipped with questions of counting operations in English that are appropriate for the level students. The core stage is the implementation carried out by providing training in writing arithmetic in English through the game take a number for banking administration management students at ASM Mataram. The last stage is the evaluation carried out by giving some questions on the number counting operations in English that are done by students in accordance with the material that bas been delivered, and comparing the results of the comparison before and after the training is given. Based on the implementation of the activity, the results showed that the arithmetic operations writing training had a good impact on mathematics and mastery of English. The addition of the game take a number aims to refresh the minds of students so that they can work on the questions while playing, as well as training the foresight, speed and accuracy in listening, writing, counting and adding numbers previously read in English.
\end{abstract}

Keywords: Count operations, English, Take a number game

\begin{abstract}
Abstrak: Pelaksanaan kegiatan ini dilakukan dengan tujuan untuk meningkatkan kemampuan mahasiswa Manajemen Administrasi Perbankan ASM Mataram dalam penulisan operasi hitung menggunakan bahasa inggris baik dalam notasi matematika dan penulisan bilangan ratusan (hundreds) dan ribuan (thousands) dalam bahasa Inggris. Tahapan dari kegiatan ini diawali dengan tahap awal (persiapan), tahap inti (pelaksanaan) dan tahap akhir (evaluasi). Tahap awal yaitu persiapan, pada tahap ini dilakukan observasi awal, pengumpulan materi mengenai tata cara penulisan operasi hitung matematika dalam bahasa Inggris baik penulisan notasi matematika dan penulisan bilangan dalam bahasa Inggris serta dilengkapi dengan soal-soal operasi hitung bilangan dalam bahasa Inggris yang sesuai untuk tingkat mahasiswa.. Tahap
\end{abstract}

Islamika : Jurnal Keislaman dan Ilmu Pendidikan

Volume 2, Nomor 1, Januari 2020; 120-128

https:// ejournal.stitpn.ac.id/index.php/islamika 
inti yaitu pelaksanaan dilakukan dengan memberikan pelatihan penulisan operasi hitung dalam bahasa Inggris melalui game take a number bagi mahasiswa manajemen administrasi perbankan di ASM Mataram. Tahap terakhir yaitu evaluasi dilakukan dengan cara memberikan beberapa soal-soal operasi hitung bilangan dalam bahasa Inggris yang dikerjakan oleh mahasiswa sesuai dengan materi yang sudah disampaikan, serta membandingkan hasil perbandingan sebelum dan sesudah diberikan pelatihan. Berdasarkan pelaksanaan kegiatan, hasilnya menunjukkan bahwa pelatihan penulisan operasi hitung memberikan dampak yang baik dalam bidang matematika dan penguasaan bahasa Inggris. Adapun penambahan game take a number bertujuan untuk merefresh pikiran mahasiswa agar dalam mengerjakan soal bisa sambil bermain, ini sekaligus melatih kejelian, kecepatan dan ketepatan dalam mendengar, menulis, menghitung serta menjumlahkan bilangan yang sebelumnya dibacakan dalam bahasa Inggris.

Kata Kunci: Operasi hitung, Bahasa inggris, Game take a number

\section{PENDAHULUAN}

Pendidikan pada zaman sekarang ini sangatlah penting bagi setiap orang, apalagi di zaman yang serba canggih seperti sekarang ini. Di era globalisasi yang sangat modern ini, pendidikan sangatlah penting, pada zaman ini kita di tuntut untuk belajar secara keras jika tidak mau ketinggalan jauh dengan bangsa-bangsa lain. Jadi, sudah seharusnya semua bangsa terfokus dan menyiapkan pendidikan dengan sebaikbaiknya, dari TK, SD, SMP, SMA, sampai ke perguruan tinggi. Begitu pentingnya pendidikan bagi kita semua, namun seiring dengan berkembangnya zaman, pendidikan semakin mahal. Itu terbukti dengan banyaknya anak Indonesia yang tidak dapat mengenyam bangku pendidikan. Pemerintah seharusnya memikirkan, menemukan jalan keluar, dan mengeluarkan kebijakan tentang pendidikan, karena pendidikan adalah satu upaya untuk meningkatkan mutu bangsa. Jika anak-anak Indonesia dapat mengenyam pendidikan setinggi-tingginya maka sudah pastitah bangsa Indonesia dapat bersaing dengan negara-negara lain. Karena pemuda-pemudi Indonesia merupakan tulang punggung negara dan sudah selayaknyalah mereka dapat pendidikan yang bermutu dan berkualitas, tanpa perlu mengeluarkan biaya yang sangat mahal. Berhubungan dengan pendidikan khususnya pendidikan di tingkat perguruan tinggi, salah satunya adalah Akademi Manajemen dan Sekretari (ASM) Mataram merupakan salah satu perguruan tinggi swasta yang menekankan mahasiswa pada kemampuan (skill) yang berhubungan dengan administrasi, perkantoran dan 
perbankan yang mana mata kuliah yang mereka ampu lebih mengacu pada perhitungan secara matematika (mathematically) baik itu pembukuan maupun akunting.

Matematika adalah bahasa simbol, ilmu deduktif yang tidak menerima pembuktian secara induktif, ilmu tentang pola keteraturan dan struktur yang terorganisasi, mulai dari unsur yang tidak didefenisikan ke unsur yang didefenisikan, ke aksioma atau postulat, dan akhirnya ke dalil ${ }^{1}$. Matematika adalah pola pikir, pola mengorganisasikan pembuktian yang logic, matematika itu adalah bahasa yang menggunakan istilah yang didefinisikan secara cermat jelas dan akurat, representasinya dengan simbol dan padat, lebih berupa bahasa simbol mengenai ide (gagasan) dari pada mengenai bunyi ${ }^{2}$.

Pada saat ini sejatinya pembelajaran matematika tidak hanya dipelajari oleh siswa baik di tingkat SD, SMP, maupun SMA. Tetapi, pembelajaran matematika pun kini diperdalam di tingkat perguruan tinggi seperti di ASM Mataram khususnya pada program studi Manajemen Administrasi Perbankan (MAP) yang mana para mahasiswa akan mempelajari mata kuliah yang berhubungan dengan operasi hitung matematika dimulai dari bilangan puluhan, ribuan, bahkan ratusan. Satu hal yang lebih ditekankan akan pentingnya mempelajari operasi hitung dengan menggunakan bahasa Inggris, ini dikarenakan nantinya dalam penghitungan mata uang tidak hanya menggunakan mata uang indonesia yaitu rupiah (Rp) tetapi tentu saja akan menggunakan mata uang (currency) asing seperti dollar (USD). Itulah sebab pentingnya mempelajari bahasa inggris khususnya di bidang matematika bagi mahasiswa MAP ASM Mataram.

Pramudita dan Anugraheni ${ }^{3}$ menggambarkan tingkat penguasaan siswa pada siswa pendidikan guru sekolah dasar Universitas Katolik Atma Jaya, khususnya aspek kognitif matematika dasar dan rujukan bahasa Inggris. Penelitian ini bertujuan untuk 1) pemetaan penguasaan matematika siswa dan relevansinya, 2) pemetaan siswa penguasaan Bahasa Inggris dan relevansinya dimana hasil penelitian ini menunjukkan

\footnotetext{
${ }^{1}$ Roza, Y., Solfitri, T., dan Siregar, S.N. (2014). Pengenalan Konsep Operasi Hitung Bilangan Melalui Permainan Congklak Dalam Pembelajaran Matematika. Jurnal Al-Khwarizmi Vol.2 No. 1

${ }^{2}$ Karso. (1992). Interaksi dan Motivasi Belajar Mengajar. Jakarta : Rajawali Pers

3 Pramudita, Wahyu., dan Anugraheni, Indi. (2017). Studi Penguasaan Matematika Dan Bahasa Inggris Mahasiswa Program Studi Pendidikan Guru Sekolah Dasar (PGSD). Jurnal Scholaria Vol.7 No.1
} 
bahwa kemampuan matematika siswa dianggap baik dan bahasa Inggris kemampuannya cukup

Berdasarkan hasil dari penelitian diatas, maka dalam pengabdian ini ingin membuktikan bahwa sebagian besar mahasiswa telah memahami bidang matematika dan penguasaan dalam bidang bahasa Inggris lebih dari cukup khususnya operasi hitung bilangan dan juga notasi matematika seperti penambahan, pengurangan, perkalian dan juga pembagian. Namun, mereka belum memahami bagaimana bentuk operasi hitung dengan menggunakan bahasa inggris. Penulisan angka atau bilangan yang terkadang agak berbeda dengan penyebutannya menjadi salah satu masalah yang dihadapi oleh mahasiswa. Penyampaian materi melalui game take a number diharapkan dapat membantu mahasiswa untuk lebih memahami bilangan dalam bahasa Inggris karena memberikan selingan games-games yang menyenangkan yang berhubungan dengan materi pembelajaran tersebut akan dapat me-refress otak mereka sejenak, sehingga dapat meningkatkan pengetahuan dan minat mahasiswa terhadap matematika khususnya operasi hitung dalam bahasa Inggris.

Selain untuk memberikan pengetahuan tentang salah satu cara untuk meningkatkan pengetahuan mahasiswa dalam penulisan notasi matematika pada mahasiswa, pelaksanaan kegiatan ini bertujuan untuk meningkatkan kemampuan mahasiswa Manajemen Administrasi Perbankan ASM Mataram dalam penulisan operasi hitung menggunakan bahasa inggris baik dalam notasi matematika dan penulisan bilangan ratusan (bundreds) dan ribuan (thousands) dalam bahasa Inggris.

Selanjutnya sasaran yang ingin dicapai dari kegiatan ini yaitu mahasiswa manajemen administrasi perbankan ASM Mataram mampu menguasai penulisan operasi hitung matematika dalam bahasa Inggris baik penulisan notasi matematika dan penulisan bilangan dalam bahasa Inggris.

\section{METODE KEGIATAN}

Permasalahan yang muncul dari hasil observasi oleh Tim Pelaksana Pengabdian, diketahui bahwa mahasiswa program studi Manajemen Administrasi Perbankan di ASM Mataram belum sepenuhnya menguasai operasi hitung bilangan khususnya dalam bahsa Inggris, pun mereka telah menguasai operasi hitung tetapi 
untuk penulisan dan penyebutan bilangan ratusan (hundreds) dan ribuan (thousands) dalam bahasa Inggris masih sering terjadi kesalahan. Di satu sisi memang mahasiswa administrasi perbankan hanya ditekankan untuk menguasai operasi hitung tetapi dikarenakan pentingnya bahasa Inggris nantinya ketika mereka memasuki dunia kerja dalam bidang perbankan, mereka tidak hanya melakukan transaksi dalam rupiah saja tetapi juga dalam mata uang asing dengan nasabah yang mungkin berasal dari luar negeri. Sebab itulah pentingnya menguasai operasi hitung bilangan dalam bahasa Inggris. Berdasarkan permasalahan yang ada, maka salah satu solusi yang dapat diberikan adalah memberikan pelatihan penulisan operasi hitung dalam bahasa Inggris melalui game take a number. Melalui game ini diharapkan agar mahasiswa lebih memahami penyampaian materi. Adapun penggunaan game take a number ini sekaligus melatih konsentrasi setiap mahasiswa. Dengan meningkatnya konsentrasi akan memeberikan dampak yang baik untuk penguasaan materi.

Metode pelaksanaan pengabdian pelatihan bagi mahasiswa Manajemen Administrasi Perbankan ini terbagi menjadi 3 (tiga) tahap, yakni

1. Tahap awal

Pada tahap awal dilaksanakan observasi dan penyiapan materi pelatihan yang dilengkapi soal-soal operasi hitung bilangan dalam bahasa Inggris yang sesuai untuk tingkat mahasiswa.

2. Tahap pelaksanaan

Tahap kedua adalah tahap pelaksanaan berupa pelatihan penulisan operasi hitung dalam bahasa Inggris melalui game take a number bagi mahasiswa manajemen administrasi perbankan di ASM Mataram.

3. Tahap akhir

Tahap akhir, yakni evaluasi berupa soal-soal operasi hitung bilangan dalam bahasa Inggris yang dikerjakan oleh mahasiswa sesuai dengan materi yang sudah disampaikan, serta membandingkan hasil perbandingan sebelum dan sesudah diberikan pelatihan. 


\section{PELAKSANAAN KEGIATAN}

Kegiatan pelatihan di program studi Manajemen Administrasi Perbankan di ASM Mataram ini dibagi menjadi tga tahapan, yaitu; tahap awal (persiapan), tahap inti (pelaksanaan) dan tahap akhir (evaluasi).

1. Tahap 1 (Persiapan)

Pada tahap ini dilakukan observasi awal dan juga wawancara. Adapun hal ini bertujuan untuk mengetahui tingkat pemahaman mahasiswa manajemen administrasi perbankan mengenai operasi hitung bilangan, khususnya dalam bahasa Inggris. Dengan mengetahui tingkat pemahaman mahasiswa, maka secara tidak langsung dapat membantu tim pemateri untuk menyiapkan materi yang memang tingkatannya lebih dari materi yang mereka telah pahami sebelumnya, seperti bilangan ratusan (bundreds) dan ribuan (thousands). Materi pelatihan akan diberikan dalam bentuk slide powerpoint dimana terdapat beberapa operasi hitung bilangan yang kemudian akan dibacakan dan dijelaskan dalam bahasa Inggris oleh tim.

2. Tahap 2 (Pelaksanaan)

Pada tahap ini dilakukan pemberian pelatihan penulisan operai hitung dalam bahasa Inggris melalui game take a number dimana mahasiswa akan meletakan setiap bilangan dengan operasi hitung yang benar sesuai dengan apa yang telah dibacakan oleh tim pemateri. Adapun operasi hitung yang akan digunakan dalam pelatihan ini meliputi penambahan (addition), pengurangan (subtraction), perkalian (multiplication), dan pembagian (division) atau dalam notasi matematika berupa,,$+- x$, dan :

Adapun menurut $\mathrm{Al}$ Ihsan ${ }^{4}$ jenis bilangan yang akan diberikan sebagai materi pelatihan ada 2 yaitu

\section{a. Ratusan (hundreds)}

Penulisan angka ratusan dalam bahasa Inggris seringkali ditmbahakan akhiran $-s$ padahal seharusnya bilangan tersebut di baca tanpa akhiran $-s$ seperti misalnya:

${ }^{4}$ Al Ihsan. (2017). Mengucapkan Berbagai Jenis Penggunaan Angka Dalam Bahasa Inggris. Diperoleh dari https://www.kunciinggrisweb.wordpress.com/2017 Diakses tanggal 16 Nopember 2018 
200 - "Two hundred" bukan "two hundreds"

350 - Three hundred and fifty five"

425 - Four hundred and twenty-five

Adapun penggunaan kata "and" sebelum dua digit angka terakhir adalah pilihan dapat digunakan (British-English) tetapi juga dapat tidak digunakan (American-English).

b. Ribuan (thousands)

Sama halnya dengan penulisan bilangan bundred penulisan thousand juga tidak memerlukan penambahan akhiran $-s$ serta tetap menggunakan bilangan bundred jika dibutuhkan seperti:

15,560 - fifteen thousand five hundred andsixty

38,247 - thirty eight thousand two hundred and forty-seven

94, 583 - ninety four thousand five hundred and eighty-three

786,450 - seven hundred eighty-six thousand four hundred fifty

\section{c. Tahap 3 (Evaluasi)}

Pada tahap ini dilakukan evaluasi dari pelaksanaan penelitian yang dilakukan dengan memberikan beberapa soal operasi hitung bilangan yang dibacakan dalam bahasa Inggris oleh tim pemateri melalui game take a number dimana mahasiswa akan menulis dan meletakkan bilangan ratusan (bundreds) dan ribuan (thousands) dengan benardi selembar kertas, dan hasilnya setelah dicek dan dikoreksi terlihat bahwa mahasiswa dapat menulis bilangan ratusan dan ribuan dengan tepat bahkan hanya beberapa mahasiswa saja yang melakukan kesalahan dalam pemisahan antara bilangan ratusan dan ribuan. Hal ini menunjukkan adanya perbedaan yang signifikan dalam hal tingkat pemahaman mahasiswa manajemen administrasi perbankan melalui media game take a number atau meletakan angka yg sesuai dalam suatu bilangan.

\section{HASIL dan PEMBAHASAN}

Secara khusus hasil dari kegiatan yang dilakukan adalah sebagai berikut :

1. Mahasiswa Manajemen Administrasi Perbankan mampu memahami tentang operasi hitung bilangan ratusan (hundreds) dan ribuan (thousands), khususnya dalam bahasa Inggris. 
2. Melalui media game take a number mahasiswa dilatih dalam hal konsentrasi, kejelian, dan daya ingat agar dapat merekam bacaan bilangan dalam bahasa Inggris dan menjumlahkannya dalam bentuk notasi bilangan matematika

3. Melalui pelatihan ini mahasiswa dilatih untuk mengembangkan kemampuan dalam berhitung dalam matematika dan bahasa Inggris

Dengan di latihnya kemampuan mahasiswa dalam menggunakan bilangan ratusan (bundreds) dan bilangan ribuan (thousands) tentunya akan memberikan dampak yang baik dalam bidang matematika dan penguasaan bahasa Inggris yang tentu saja akan berdampak positif juga kelak ketika mereka telah memasuki dunia kerja perbankan untuk menghitung mata uang yang bukan hanya mata uang Indonesia tetapi juga mata uang asing. Adapun penambahan game take a number bertujuan untuk merefresh pikiran mahasiswa agar dalam mengerjakan soal bisa sambil bermain, ini sekaligus melatih kejelian, kecepatan dan ketepatan dalam mendengar, menulis, menghitung serta menjumlahkan bilangan yang sebelumnya dibacakan dalam bahasa Inggris.

\section{KESIMPULAN}

Operasi hitung matematika merupakan salah satu hal yang telah dipelajari dari tingkat sekolah dasar hingga perguruan tinggi, namun memahami penggunaan operasi hitung dalam bahasa inggris pun sangat penting, khususnya bagi mahasiswa manajemen administrasi perbankan ASM Mataram. Dan dengan di latihnya kemampuan mahasiswa dalam menggunakan bilangan ratusan (hundreds) dan bilangan ribuan (thousands) tentunya akan memberikan dampak yang baik dalm bidang matematika dan penguasaan bahasa Inggris yang tentu saja akan berdampak postif juga kelak ketika mereka telah memasuki dunia kerja perbankan untuk menghitung mata uang yang bukan hanya mata uang Indonesia tetapi juga mata uang asing. Adapun penambahan game take a number bertujuan untuk merefresh pikiran mahasiswa agar dalam mengerjakan soal bisa sambil bermain, ini sekaligus melatih kejelian, kecepatan dan ketepatan dalam mendengar, menulis, menghitung serta menjumlahkan bilangan yang sebelumnya dibacakan dalam bahasa Inggris. Dengan demikian, setelah mengetahui cara penulisan operasi hitung dalam bahasa Inggris ini diharapkan mahasiswa agar lebih cakap dan cekatan dalam mengembangkan keahlian 
dalam operasi hitung bilangan ratusan (bundreds) dan ribuan (thousands) khususnya dalam bahasa Inggris.

\section{DAFTAR PUSTAKA}

Al Ihsan. (2017). Mengucapkan Berbagai Jenis Penggunaan Angka Dalam Babasa Inggris. Diperoleh dari https://www.kunciinggrisweb.wordpress.com/2017 Diakses tanggal 16 Nopember 2018

Karso. (1992). Interaksi dan Motivasi Belajar Mengajar. Jakarta : Rajawali Pers

Pramudita, Wahyu., dan Anugraheni, Indi. (2017). Studi Penguasaan Matematika Dan Bahasa Inggris Mahasiswa Program Studi Pendidikan Guru Sekolah Dasar (PGSD). Jurnal Scholaria Vol.7 No.1

Roza, Y., Solfitri, T., dan Siregar, S.N. (2014). Pengenalan Konsep Operasi Hitung Bilangan Melalui Permainan Congklak Dalam Pembelajaran Matematika. Jurnal Al-Khwarizmi Vol.2 No. 1 